Article

\title{
Capturing Agroecosystem Vulnerability and Resilience
}

\author{
Jeroen C. J. Groot ${ }^{1, *}$, José Cortez-Arriola ${ }^{1}$, Walter A. H. Rossing ${ }^{1}$,
} Ricardo D. Améndola Massiotti ${ }^{2}$ and Pablo Tittonell ${ }^{1}$

1 Farming Systems Ecology Group, Wageningen University \& Research, P.O. Box 430, Wageningen 6700 AK, The Netherlands; jcorteza@terra.com.mx (J.C.-A.); walter.rossing@wur.nl (W.A.H.R.); tittonell.pablo@inta.gob.ar (P.T.)

2 Graduate Program in Animal Science, Chapingo University, Km. 38.5 Carretera, México-Texcoco, Texcoco C.P. 56230, Mexico; r_amendola@yahoo.com

* Correspondence: Jeroen.Groot@wur.nl; Tel.: +31-317-485-924

Academic Editor: Hossein Azadi

Received: 25 October 2016; Accepted: 16 November 2016; Published: 22 November 2016

\begin{abstract}
Vulnerability and resilience are two crucial attributes of social-ecological systems that are used for analyzing the response to disturbances. We assess these properties in relation to agroecosystem buffer capacity and adaptive capacity, which depend on the 'window of opportunities' of possible changes in terms of selected performance indicators, i.e., the solution space. The vulnerability of the system was quantified as the distance of performance indicators between original and disturbed systems. The buffer capacity was derived from the size of the solution space that could be obtained after reconfiguration of farm components (crops, animals, fertilizers, etc.) that were present on the original farm, whereas the assessment of adaptive capacity was derived in a similar way, but after allowing innovation by introducing new components to the farm. To illustrate the approach, we applied these concepts to two dairy farms in Northwest Michoacán, Mexico. After a disturbance resulting in a fodder maize yield decline, both economic profitability and soil organic matter inputs were reduced. The scope for recovery was different between the farms, but the projected improvements in profitability and organic matter inputs would require considerable changes in the farm configurations, and thus flexibility in farm management. High resilience requires a farmer with the managerial ability to make the required changes to move through the proposed solution space. The approach we present here offers a generic quantitative assessment of vulnerability and resilience concepts, based on a combined assessment of the social and ecological dimensions of agroecosystems.
\end{abstract}

Keywords: multi-objective optimization; buffer capacity; adaptive capacity; solution space

\section{Introduction}

Hundreds of millions of farmers worldwide are confronted with increasing uncertainty due to gradual changes and sudden fluctuations in external drivers associated with demography, climate, market prices for inputs and products, policies, and geo-political conflicts [1-4]. In order to maintain their livelihoods, and to secure the supply of food for a growing global population and the provision of other ecosystem services from rural landscapes, these agroecosystem managers have to minimize their vulnerability and should be able and willing to adapt to be resilient to changing circumstances.

Resilience and vulnerability are two attributes of socio-ecological systems that reflect their behavior in response to perturbations at a local, regional, or global level. Vulnerability represents the susceptibility to harm to the performance of a system from exposure to disturbances associated with environmental and social change [5,6], whereas resilience focuses on the capacity of the system to absorb disturbances and reorganize while undergoing change so as to still retain the same function and 
structure [6-8]. These concepts have been useful in providing insight into the complexities of natural resource management in social-ecological systems. Their most salient application has been in the metaphoric sense, to illustrate the dynamics of systems development cycles (adaptive cycles), to show interrelations among scales within coupled social-ecological systems, and to indicate the necessity of preparedness for disturbances and adaptation at all hierarchical levels $[9,10]$.

Disturbances differ in the intensity, duration, and frequency of the impact. Shocks denote sudden perturbations for a short period of time, whereas stresses affect a system uninterruptedly for longer time span (years) and with certain level of predictability [11]. In agricultural systems, disturbances to farms negatively impact on system productivity and profitability. Disturbances can be classified [8] as economic (input price increase, output price decrease, inputs availability, access to markets, and uncertainty on land tenure); climatic (weather shocks like extreme temperatures and precipitation rates); and management-related (plant pests, animal diseases, overharvesting, and overgrazing). In dairy farm systems, social, environmental, and economic domains are strongly linked to the animal and crop subsystems, where on-farm grassland or forage production is used as an alternative to reduce the external dependency of feeding and feeding costs, to recycle nutrients, and as source of income. Due to the complex interrelations among subsystems and the damage that these systems might suffer, it is relevant to identify the disturbance and to quantify the magnitude of the impacts in the social, economic, and environmental system domains.

Different theoretical models and practical approaches are available to understand and assess vulnerability and resilience in agricultural systems at different space and time levels [11-16]. Nonetheless, the challenge of quantitatively analyzing vulnerability and resilience at the farm systems level still remains. Such approaches could contribute to design of more resistant and resilient farms [6,11]. Multiple authors (e.g., [12,17]) have pointed out the need for approaches that use numerical analysis in the assessment of vulnerability and resilience.

Available quantitative approaches that make the concepts of resilience and vulnerability operational include dynamic systems analysis and the quantitative techniques, which support adaptive management. In dynamic systems analysis, ecological systems have been modeled in terms of differential equations that simulate the changes in slow and fast state variables. This method has been effective at demonstrating that ecosystems have multiple stable states and that they can collapse due to inappropriate too intensive management [12,18-22]. After such a regime shift to a degraded state, recovery to a desirable state might be difficult or impossible. The occurrence of over-use of systems or of their components has been attributed to the lack of feedback and correction mechanisms in the human dominated world, in particular in the socio-institutional and economic parts of systems [23,24].

Here we apply resilience and vulnerability in an illustration using quantitative farming systems models. Both dynamic and static quantitative representations of farming systems have been put forward in the literature. For instance, [25,26] developed a dynamic model of a dairy farm that is characterized by three state variables describing organic nitrogen, carbon, and inorganic nitrogen pools, respectively and grassland and cattle management that intervenes in the rates of change of the states. In contrast to these relatively simple, analysis-oriented models, [27] presents a dynamic model of an arable farm with a large number of state variables describing soil-crop-atmosphere relations on different fields and their cross-field interactions, aiming at representativeness of reality. Static farming system models represent key elements of farming systems as balances of economic, social, and environmental indicators, aggregating changes over time periods of typically a year (see review by [28]). Static farm models are generally far more tractable than dynamic farm models, but inherently lack dynamic feedbacks. Nevertheless, they may be applied in a semi-dynamic manner where the researcher re-initializes the model to mimic a disturbance. To our knowledge, such application is novel and may open up a new line of farming systems research.

The aim of this study was to present a quantitative approach to analyze and assess vulnerability and resilience in agricultural systems. The approach is illustrated through the analysis of these properties on family-based (FB) and semi-specialized (SS) dairy farms in Marcos Castellanos, 
Michoacán, Mexico, that undergo a shock disturbances in the form of a reduction in forage maize production. Alternative management options to strengthen system resilience (hereafter called 'innovations') are evaluated using a multi-objective farm-scale optimization model. This approach represents a way to operationalize and to reduce subjectivity and abstractness of the concepts of vulnerability and resilience.

\section{Conceptual Approach}

The evolving nature of complex adaptive systems has been conceptualized as a continuous adaptive cycle [29] of phases of growth, accumulation, restructuring, and renewal. The degree to which social-ecological systems can perpetuate these cycles depends on three general system properties [30]. The first property is the 'potential' of a system, which is determined by the availability of options for future development that allow a system to continue functioning at a desired level for a predefined set of state variables after a disturbance. The other properties are the 'controllability' and 'resilience' of the system, which reflect the rigidity or flexibility for adaptation and change and determine the degree to which a system is affected by and can recover from a disturbance [30].

The 'potential' of the system can be associated with two other ecosystem properties, buffer capacity and adaptive capacity $[19,31]$. We conceptualize buffer capacity as the ability of the system to continue performing at a similar performance level after a disturbance without structural changes in the number or diversity of components and processes in the system. In systems that are characterized by high diversity, the probability of the presence of redundant components and links is high, which supports the buffer capacity [32] because links and flows can be redirected to support crucial system processes without compromising other vital functions. Adaptive capacity is defined as the ability to reconfigure and recover performance after new components have been introduced into the system.

Agroecosystems are coupled human-environment systems wherein the farmer, who participates in a larger socio-institutional network, manages part of the ecosystem with the aim to eventually harvest crop and/or animal products either for self-consumption or the market. The ecological part of the system can be either strongly dependent on biological processes such as nutrient cycling through animal manures and crop residues and pest suppression by natural enemies of crop pests, or more dependent on external inputs that can be imported from communal resources (e.g., food, feed, bedding for animals) or purchased on markets (e.g., seeds, fertilizers, pesticides, feeds). The concept of the 'potential' of the system is reflected in the ways the farmer can reconfigure crops, animals, resources, and management practices on his farm to reach a desired productive, environmental, and social outcome given the biophysical, socio-economic, and political environment in which he operates.

A disturbance can be a pest or drought or product price decline that can negatively affect the farming system performance. The farmer can respond by reconfiguring the farm with changes in for instance crop areas, animal numbers, amounts of inputs, selected market channels, or management practices to compensate for the effect of the disturbance. The available options for adjustment of the system with existing components and resources can be considered the 'buffer capacity'. When the farmer decides to introduce new crops, animals, inputs, or practices the required adjustment and reconfiguration (both in the ecological system and in farm management) is expected to be considerably larger and is reflected in the 'adaptive capacity'. This illustration of the concepts for an agroecosystem demonstrates that, besides the ecological (self-)organization, the farmer, his flexibility and skills, and his cognitive and managerial capacities will determine the chosen strategy of adaptation and the final effectiveness of reconfiguration, and thus agroecosystem resilience.

All possible combinations of values of state variables constitute the 'window of opportunities' or 'solution space' for a particular system [33]. The potential of a system (P), resulting from buffer and adaptive capacity, can be derived from the size of the solution space, which defines the options for adjustment of the system. The solution space is delimited by the Pareto frontier (or Pareto surface when more than two performance criteria are included in the analysis), and for assessment of resilience we consider only options that perform at least as good as the existing system. The Pareto 
frontier can be established using multi-objective optimization, and the area (in 2 dimensions), volume (3 dimensions), or hyper volume ( $>3$ dimensions) of the solution space can be calculated [34], for instance, relative to a given reference point that represents the existing situation. This is demonstrated in Figure 1, wherein only the portion of the solution space with improvements in two system states (productivity and environmental quality in this case) relative to the existing situation after a disturbance is depicted. The buffer capacity (area B in Figure 1a) is estimated as the solution area corresponding to the reconfiguration of links and flows among the components that are already in the system. The adaptation capacity (area A in Figure 1a) is estimated as the expansion of the solution area when new components are introduced in the system. The potential $(\mathrm{P})$ is estimated as the sum of areas A and B.
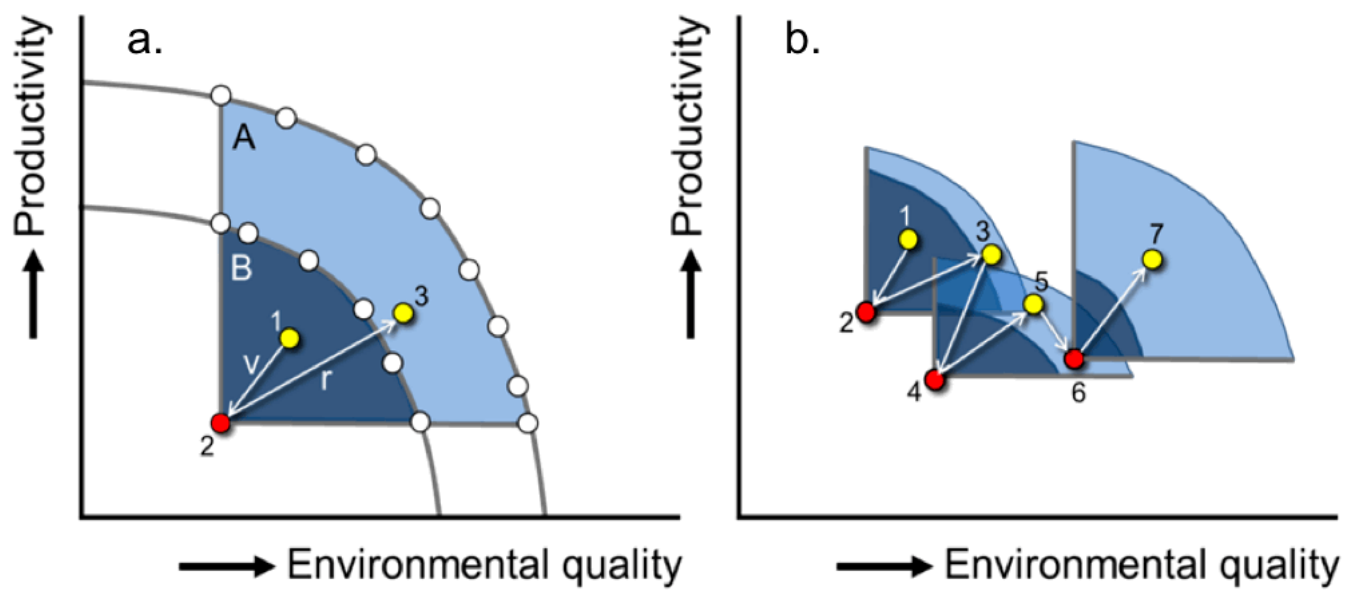

Figure 1. Portions of solution spaces with future options that perform better for two generic objectives, productivity and environmental quality, relative to disturbed states denoted by red symbols. (a) After a disturbance, the system states change following the arrow from Point 1 to Point 2 (vulnerability v is the distance between points 1 and 2), and move to a more desirable state such as Point 3 (resilience $r$ is the distance between points 2 and 3). Area A represents the adaptive capacity and B the buffer capacity of the system after the disturbance. Potential P is calculated are the sum of areas A and B. White symbols denote alternatives for the current system; (b) The potential of a system at consecutive moments in time, with changing attained states (points 1,3,5, and 7) and after disturbances (points 2, 4, and 6).

Disturbances result in a deterioration of the performance of at least one of the state variables. This is visualized by the change in system state from point 1 to point 2 in Figure 1a. The distance (here measured in unit of ordinate per unit abscissa) between these points represents the vulnerability (v) of the system to the disturbance. P represents the potential range of future development options that all differ in the degree of change that is needed to move from the disturbed state to a new, more desirable configuration. Which option will actually be realized (for instance, point 3 in Figure 1a) depends on the ability to rebalance interactions and flows within the system, which have to be rebalanced through (self-)organization. This requires flexibility, learning, and experimentation. It can be expected that, in many cases, larger improvements in performance of state variables relative to the initial situation will also require larger adjustments in system configuration and organization. The distance between points 2 and 3 is the recovery (r) of the system. We propose to estimate the resilience as $R=r / v$, denoting the ability of a system to recover after a shock.

The size and shape of the solution space will change continuously since the system and its environment are subject to adjustments, for instance in bio-physical environment, or due to technological and socio-institutional innovations [33]. For instance, declines in soil fertility resulting from erosion or invasion of the system by a new pest will reduce crop yields and productive farm performance; increased water infiltration and nutrient leaching due to enhanced precipitation associated with climatic change will affect the environmental impact of farming activities; changes in policy regimes and introduction of new taxation or subsidy schemes will alter the economic revenues 
from the agroecosystem. As a consequence, the vulnerability and resilience of the system should also be considered as dynamic properties. This is illustrated in Figure 1b, which shows a sequence of disturbed and recovered system states.

\section{Materials and Methods}

\subsection{Regional Characterization}

The municipality of Marcos Castellanos is located North-west of Michoacán State (19 ${ }^{\circ}$ northern latitude and $103^{\circ}$ western longitude) at altitudes between 1500 and 2400 masl. The area of this municipality is 23,285 ha, and $86 \%$ of it is classified as grazing land (mainly constituted by native species of grasses) and $12 \%$ is cropland (mostly for maize forage production) [35]. The climate is classified as temperate with one main rainy season between June and October; precipitation and temperature averages are $798 \mathrm{~mm}$ and $18.9^{\circ} \mathrm{C}$. Due to the prolonged dry season (from November to May) and the prohibition to exploit the aquifer for agricultural activities since 1987, forage production in the grazing lands and crop lands is negligible in this period.

\subsection{Dairy Farm Characterization}

Small family-based and somewhat larger and more intensive semi-specialized dairy farms represent the majority of farms present in the study region [36,37]. For this study, two medium-intensive dairy farms with cattle density between 0.8 to 1.2 livestock units (LU) per ha representing family-based (FB) and semi-specialized (SS) enterprises were selected as pilot farms. We take a pilot-farm approach to illustrate the presented concept and analysis approach. The two medium-intensive farms were selected because their productivity levels and efficiencies are similar and their external dependency is relatively low compared to more intensive dairy systems in the region [36]. More detailed diagnosis of a larger number of dairy farms from various types have been presented elsewhere [36-38]. The dairy farms in the study region are characterized by using Holstein Frisian cows and crosses of this breed with Zebu and Brown Swiss. Cows are milked twice daily, and the milk produced is sold as raw milk directly to middlemen or local dairy industries. During the milking time, the lactating cows receive concentrate to complement the grazed and conserved forage; the supplied amount of concentrate is large and varies between 4.5 and $8.4 \mathrm{~kg}$ dry matter $\mathrm{LU}^{-1}$. day $^{-1}$ during the rainy season, and between 7 and $7.6 \mathrm{~kg} \mathrm{DM} \mathrm{LU} \mathrm{L}^{-1} \cdot \mathrm{d}^{-1}$ during dry season. Maize forage is mainly produced in the farms exclusively for cattle feeding, and it is conserved as silage or stover (whole plant hay) to compensate for the lack of forage from the grazing lands during the dry season. However, it is not exclusive for this season neither is it the only source of conserved forage in the region, since hay of alfalfa, annual ryegrass, and chickpea represent alternative sources of forage available in the regional market. For the maize crop management, herbicides for weed control, insecticide for Phyllophaga spp. pest prevention, and fertilizers with nitrogen and phosphorus are commonly applied in cropland without manuring. Basic information describing farm size, land use types, herd structure, productivity, diet composition, and labor of the selected farms is included in the supplementary material, Tables S1 (FB) and S2 (SS).

\subsection{Vulnerability and Resilience Assessment}

The FarmDESIGN model, which evaluates farm configurations and their performance on an annual basis, was used to quantify social, economic, and environmental performance indicators of the farms, and to explore solution spaces of these farms using a Pareto-based multi-objective optimization algorithm. During the optimization, the model generates alternatives of agricultural production systems by adjusting farm components (crops and animals) and inputs (for crop and animal production). These farm components are the decision variables, the values of which are drawn from predefined intervals. Subsequently, the model evaluates the generated alternatives with selected performance indicators (objectives that are either minimized or maximized) and it selects the best solutions for a next iteration of improvement on the basis of the Pareto principle [39]. In this illustration, 
the selected objectives were: maximizing farm profitability, maximizing the soil organic matter (OM) balance (as indicator of soil quality improvement), and minimizing the farm nitrogen $(\mathrm{N})$ balance (as indicator of nutrient losses to the environment). More detailed information of the operational procedure of the model is included in the supplementary material, Box 1.

Maize silage is one of the main sources of fodder during the dry season in the study region. Therefore, vulnerability was estimated by considering the impact of a reduction in forage maize production as a shock disturbance on the selected farms. After the analysis of the farm performance for the period 2009-2010, considering the decision variables and constraints listed in Tables S1 and S2, the forage maize yield was replaced by the forage maize yield of the period 2008-2009 (Table S1). In both farms, the forage maize yield was lower in 2008-2009 due to low rates of seeding and fertilizing and the incidence of fall armyworm (Spodoptera frugiperda). The vulnerability of the farms to this change was assessed by comparing the values of the objectives between the original farm and the situation with reduced forage maize production.

The newly introduced practices of forage barley cropping and manure application were evaluated as strategies of farm management to resist and to adapt the farms to reductions in forage maize yield, and to estimate farm adaptive capacity. In the model, forage barley was considered to be grown immediately following silage maize, benefitting from the last rains of the season and the residual soil moisture. This is not a common cropping practice in the study region, and information on forage barley production and use was obtained from [40]. In the model, manure was available due to collection in the stables and in the yards during the dry period.

The buffer capacity (B) and the adaptive capacity (A) areas of the farms (cf. Figure 1a) were obtained by exploring alternative farm configurations based on the ranges in decision variables as shown in Table S2, using as a starting point the perturbed farm that suffered forage maize yield loss due to $S$. frugiperda. To assess the extent of managerial changes compared to the starting point, we calculated a 'relative change index' as the sum of squared normalized changes for each of the decision variables (Equation (1)). Larger values for this relative change index indicate larger changes in management.

$$
C=\sum_{p=1}^{n}\left(\frac{x_{p, q}-x_{p, \min }}{x_{p, \max }-x_{p, \min }}\right)^{2}
$$

where:

$C=$ relative change index

$n=$ number of decision variables

$x_{p, q}=$ value of decision variable $\mathrm{p}$ for alternative $\mathrm{q}$ from the set of solutions

$x_{p, \min }=$ minimum value of decision variable $p$

$x_{p, \max }=$ maximum value of decision variable $p$

\section{Results}

\subsection{Vulnerability}

Perturbation of the FB and the SS farms by assuming maize forage production to be as low as in September 2008 resulted in a decline in profitability and soil OM balance of both farms compared to October 2009 baseline. The N balance was not affected (Figure 2; Table 1). In terms of profitability, SS was more vulnerable to the reduction in forage maize production than FB, because SS derived its income from sales of milk and forage maize, while FB depended on sales of milk only (Figure 2; Table 1). Since forage maize production contributes to the OM balance through residues that remain in the field (roots and stems) and through forage losses during harvesting and feeding, the maize yield reduction implied slight declines in the OM balance on both farms (Figure 2; Table 1). 


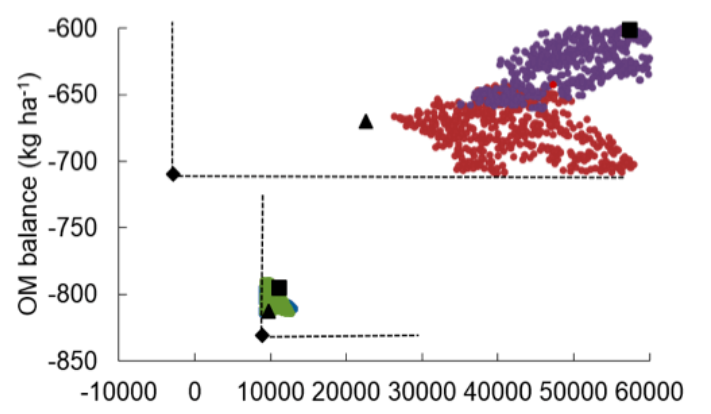

- FB options with original components

- SS options with original components

- FB options with new components

- SS options with new components

- Original performance

- After disturbance

- Selected option, illustrating resilience
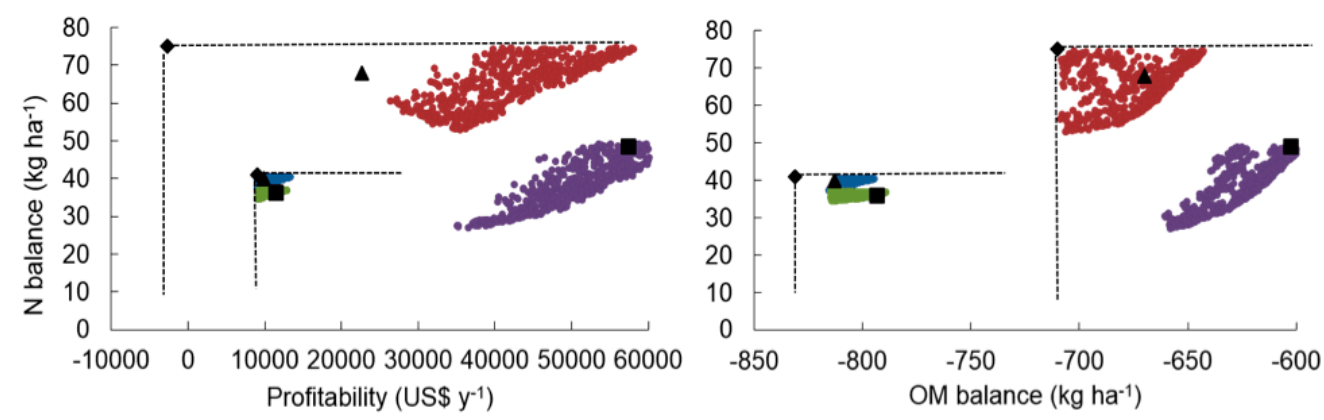

Figure 2. Original dairy farm performance $(\boldsymbol{\Lambda})$, and the response to the perturbation of forage maize yield reduction ( $)$ for family-based (FB) and semi-specialized (SS) dairy farms in Marcos Castellanos, Mexico, related to profitability, OM balance, and $\mathrm{N}$ balance as objective variables. The blue (FB) and red (SS) symbols represent buffer capacity, and the green (FB) and purple (SS) symbols display adaptive capacity (by including the new technologies of forage barley and improved manure application). To illustrate resilience, one option per farm was selected

Table 1. Vulnerability, resilience, and net change of medium intensive family-based (FB) and semi-specialized (SS) dairy farms in Marcos Castellanos, Michoacán, Mexico, after a perturbation of forage maize yield reduction and subsequent recovery by the inclusion of forage barley production and improved manure management, assessed considering profitability (US $\$ \cdot$ year $^{-1}$ ), organic matter balance $\left(\mathrm{OM}, \mathrm{kg} \cdot \mathrm{ha}^{-1}\right)$, and nitrogen balance $\left(\mathrm{N}, \mathrm{kg} \cdot \mathrm{ha}^{-1}\right)$ as objective variables.

\begin{tabular}{ccccccc}
\hline \multirow{2}{*}{ Variable } & \multicolumn{5}{c}{ FB } & \multicolumn{3}{c}{ SS } \\
\cline { 2 - 7 } & Profit & OM Balance & N Balance & Profit & OM Balance & N Balance \\
\hline Condition assessed & & & & & \\
\hline Original values & 9712 & -813 & 40 & 22,557 & -670 & 68 \\
After perturbation & 8865 & -831 & 41 & -2800 & -710 & 75 \\
Selected configuration & 11,169 & -795 & 37 & 57,398 & -601 & 49 \\
\hline Variables estimated & & & & & & 70 \\
\hline Vulnerability (v) & 847 & 18 & 1 & 25,357 & 109 & 26 \\
Recovery (r) & 2304 & 36 & 4 & 60,198 & 2.7 & 3.7 \\
Resilience (R = r/v) & 2.7 & 2.0 & 4.0 & 2.4 & & \\
\hline
\end{tabular}

\subsection{Buffer Capacity and Adaptive Capacity}

Reconfiguration of the farms with the existing farm components (crops, animals, fertilizers, feeds, etc.) provided options to improve the three objectives that were larger for the SS farm than for the FB farm. Thus, the buffer capacity as indicated by the range of Pareto optimal options in Figure 2 was much larger for SS than for FB. Introducing the new practice of growing barley after maize and assuming improved manure management offered even larger improvements in the three objectives, and demonstrated the adaptive capacity of the farms. Also, here the solution space for SS exceeded that for FB (Figure 2). 


\subsection{Required Changes in Farm Management}

The relation between the attainable improvement in the objectives and the required adjustments in farm management is illustrated for farm SS in Figure 3. To enable comparability among objectives, the objective values were normalized. As shown by the color-coded values of the relative change index (calculated as the sum of squared normalized change in the decision variables, Equation (1)), the largest adjustments in management were required to increase the organic matter balance (Figure 3).
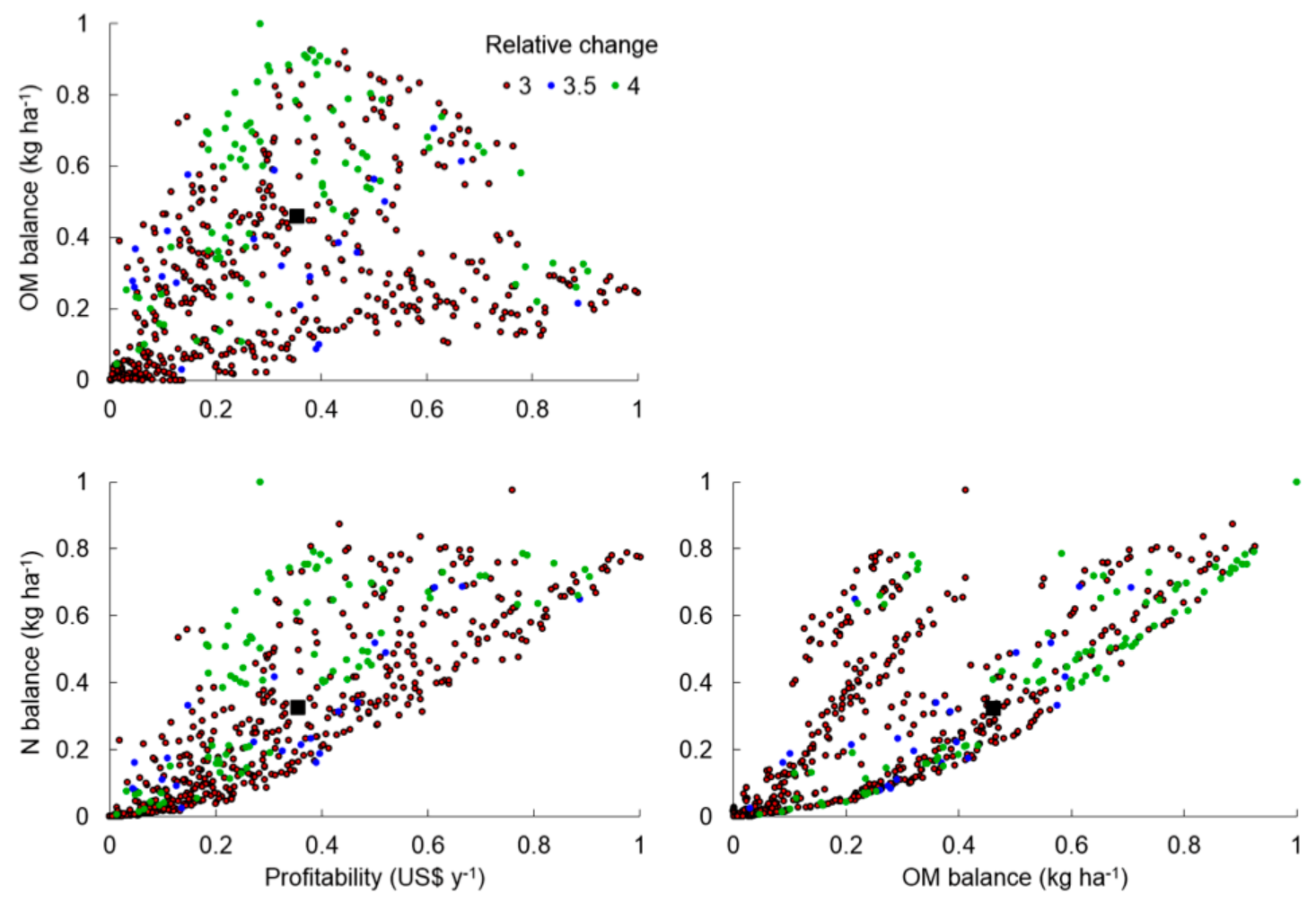

Figure 3. Required changes needed in decision variables compared to the starting position after the disturbance for semi-specialized (SS) dairy farm in Marcos Castellanos, Mexico. Objectives variables are normalized for comparability by calculating for each alternative the difference with the starting position and dividing by the objective value range. Color codes describe the sum of squared normalized change in the decision variables compared to the starting position (see Equation (1)). Larger values indicate larger required changes in management. The option selected to illustrate resilience is denoted by

\subsection{Resilience}

To illustrate the quantification of resilience $\mathrm{R}$ (Table 1), one farm configuration was selected for each of the two farms from the explorations of adaptive capacity (Figure 2). Although the absolute improvements in objective variables that could be attained (denoted as recovery $r$ ) were considerably larger for farm SS than for FB, the resilience R (calculated as the improvement relative to the absolute value of the impact of the disturbance, i.e., vulnerability v) was similar for both farms. Only for the OM balance, resilience R was larger for SS (2.7) than for FB (2.0). To reach the improvements on SS, larger adjustments in the farm configuration were needed with a relative change index of 2.9 for SS and 1.5 for FB. The actual resilience will depend on the ability of the farm managers to make the required adjustments to improve farm performance to reach the projected recovery. 


\section{Discussion}

Socio-ecological systems are highly conditioned by the human capacity to reduce vulnerability by controlling disturbances and managing adaptive capacity $[8,32]$. These systems are dynamic and strongly influenced by external factors and internal components and the interaction of biotic and abiotic variables involved. Farmers, technicians, and governments interfere intentionally in this dynamic and in the direction of changes by decision-making. The exploration of alternatives might support planners and policy-makers in the definition of policies, technicians in the search of solutions and innovations, and farmers in the implementation of changes all aimed at increasing or improving the adaptability of the systems.

By applying the presented framework to vulnerability and resilience assessment, these concepts lose abstractness by showing concrete and numerical changes that quantify and explain farm performance, and potential effects of both disturbances and a broad range of possible responses. The outcomes of the vulnerability assessment showed that both dairy farm systems were able to absorb the effects of the shock disturbance of reduced on-farm maize productivity. The vulnerability was assessed as the magnitude of the change of the performance indicators between the farm before and after the disturbance. Vulnerability was larger for the SS farm than for the FB farm, in particular in terms of profitability and to a lesser extent OM balance (Figure 2). The FB farm depended less on on-farm produced maize (and thus had a larger reliance on externally sourced feeds), which resulted a better capacity to absorb the effect of on-farm forage maize production reduction than for SS in our scenario. This scenario is valid under the current system delineation of the farm that considers markets and product prices external to the system. However, in the actual situation, the impact on profitability will also depend on the changes in maize fodder prices that could occur when the disturbance affects not only the farm under study, but reduces maize productivity at a larger scale.

The set of alternatives obtained during the exploration process showed the capacity of the farms to adjust their subsystems to the disturbance by reconfiguring their resources and diversifying the farm's production. The buffer capacity was larger for SS than for FB due to its higher diversity of available resources and greater deficiencies in baseline farm performance including factors such as poor herd structure and low milk production and crop productivity. The adaptive capacity increased after inclusion of the new management practices of forage barley cultivation after maize and manure application by enhancing the possibilities for mitigating the negative effects of the disturbance on the objective variables. The potential P of the SS farm was larger than that of FB, mainly for minimizing the $\mathrm{N}$ balance, which was the indicator that improved the most after implementation of the alternative of management. Both farms could adjust their management by reconfiguring and adjusting the management of already available resources. For maximizing profitability, SS had to intensify by increasing milk production and productivity, and sales of products (milk and maize forage). On the other hand, FB had to intensify its milk production and to diversify its sales, adding maize forage, although this implied increasing the external dependency of feedstuffs. More diversity in land-use at farm and landscape levels can lead to higher resilience against disturbances, offering more alternatives to manage the impacts [8] and to stabilize economic returns [41].

Generating multiple collections of snap-shots to create a timeline of changes in system performance and windows of opportunities, as done in our framework, can make the analysis with a static bio-economic model semi-dynamic. However, the inherent limitations of static models remain-i.e., the importance of the system state for the response to disturbance is not addressed-and the dynamics and feedbacks cannot be incorporated directly. Nevertheless, that analytical framework can be readily coupled to more complex dynamic and event-driven models. Another limitation of the illustration presented here is that it only comprised the scales of field and farm, whereas larger landscape and community studies would also be useful and relevant to assess the influence of cooperative decision-making and of policies and institutions [42-44]. Possible extensions include the evaluation of scenarios of change in the external drivers such as climatic change, demographic change, and changes in socio-institutional conditions (prices and policies), cf. [33]. 
To illustrate our concept, we only considered a single shock disturbance to assess vulnerability, one alternative to analyze resilience, and three objective variables. Nevertheless, due to the many factors and interactions between subsystems the analyses revealed to contain rich complexity, which would be difficult to assess with simple conceptual models as it is commonly proposed $[8,11,19,32]$. While conceptual models support the analysis by understanding the structures and functions of the systems under assessment, model-based quantitative analysis can enrich the analysis by demonstrating links between subsystems and considering social, economic, and environmental performance of systems after disturbance.

\section{Conclusions}

We presented a framework for quantitative analysis of vulnerability and resilience of farming systems, based on a multi-objective explorative whole-farm model that quantified buffer and adaptive capacities of the two case study farms. The results express vulnerability and resilience in terms relevant for farm assessment, thus reducing abstractness of the notions and providing leverage points for on-farm adaptation. Yet, generating meaningful analyses requires a close collaboration between farmers and researchers to gather relevant and accurate information to build the conceptual models, to define the objectives, to parameterize the simulation model, and to identify the salient disturbances and alternative practices in order to increase the buffer and adaptive capacities.

The results of the study show how a system reconfiguration can play a role in reducing the impact of disturbances and in increasing the potential capacity of agricultural systems. However, taking advantage of system resilience may require considerable change in practices and will draw on the skills, motivation, and learning capacity of the farmer.

Supplementary Materials: The following are available online at www.mdpi.com/2071-1050/8/11/1206/s1, Box 1: Details of data collection and modeling, Table S1: Forage maize production, crop management, and precipitation on medium intensive family-based (FB) and semi-specialized (SS) dairy farms in Marcos Castellanos, Michoacán, Mexico, Table S2: Decision variables (inputs and constrains) modified during the exploration of alternatives for family-based (FB) and semi-specialized (SS) dairy farms systems located in Marcos Castellanos, Michoacán, Mexico.

Acknowledgments: This research was funded by the EULACIAS project (EU FP6-2004-INCO-dev-3; contract nr 032387; http:/ / www.eulacias.org/). Our sincere gratitude goes out to all farmers that participated willingly in this research. The authors would also like to acknowledge financial support from the CGIAR Research Program (CRP) "Integrated Systems in the Humid Tropics" (Humidtropics), the CRPs MAIZE and WHEAT project "Agro-ecosystem diversity and the Trajectories and Trade-offs for Intensification of Cereal-based systems" project (ATTIC, grant agreement: A4032.09.20).

Author Contributions: Jeroen C. J. Groot developed the concept; Jeroen C. J. Groot and José Cortez-Arriola conceived and designed the modeling experiments; José Cortez-Arriola collected on-farm data; Jeroen C. J. Groot and José Cortez-Arriola analyzed the modeling results; Jeroen C. J. Groot, Walter A. H. Rossing, José Cortez-Arriola, Ricardo D. Amendola Massiotti and Pablo Tittonell wrote the paper.

Conflicts of Interest: The authors declare no conflict of interest.

\section{References}

1. Meinke, H.; Howden, S.M.; Struik, P.C.; Nelson, R.; Rodriguez, D.; Chapman, S.C. Adaptation science for agriculture and natural resource management-Urgency and theoretical basis. Curr. Opin. Environ. Sustain. 2009, 1, 69-76. [CrossRef]

2. Gornall, J.; Betts, R.; Burke, E.; Clark, R.; Camp, J.; Willett, K.; Wiltshire, A. Implications of climate change for agricultural productivity in the early twenty-first century. Philos. Trans. R. Soc. Lond. B Biol. Sci. 2010, 365, 2973-2989. [CrossRef] [PubMed]

3. Herrero, M.; Thornton, P.K.; Notenbaert, A.M.; Wood, S.; Msangi, S.; Freeman, H.A.; Bossio, D.; Dixon, J.; Peters, M.; van de Steeg, J.; et al. Smart investments in sustainable food production: Revisiting mixed crop-livestock systems. Science 2010, 327, 822-825. [CrossRef] [PubMed]

4. Suweis, S.; Carr, J.A.; Maritan, A.; Rinaldo, A.; D'Odorico, P. Resilience and reactivity of global food security. Proc. Natl. Acad. Sci. USA 2015, 112, 6902-6907. [CrossRef] [PubMed] 
5. Adger, W.N. Vulnerability. Glob. Environ. Chang. 2006, 16, 268-281. [CrossRef]

6. Miller, F.; Osbahr, H.; Boyd, E.; Thomalla, F.; Bharwani, S.; Ziervogel, G.; Walker, B.; Birkmann, J.; Van der Leeuw, S.; Rockström, J.; et al. Resilience and vulnerability: Complementary or conflicting concepts? Ecol. Soc. 2010, 15, 1-25.

7. Walker, B.H.; Abel, N.; Anderies, J.M.; Ryan, P. Resilience, adaptability, and transformability in the Goulburn-Broken catchment, Australia. Ecol. Soc. 2009, 14, 12.

8. Gitz, V.; Meybeck, A. Risks, Vulnerabilities and Resilience in a Context of Climate Change. Available online: http:/ / www.fao.org/docrep/017/i3084e/i3084e03.pdf (accessed on 9 September 2015).

9. Gunderson, L.; Holling, C.S. Panarchy: Understanding Transformations in Human and Natural Systems; Island Press: Washington, DC, USA, 2001.

10. Brand, F.S.; Jax, K. Focusing the Meaning(s) of Resilience: Resilience as a Descriptive Concept and a Boundary Object. Ecol. Soc. 2007, 12, 23. [CrossRef]

11. Darnhofer, I.; Fairweather, J.; Moller, H. Assessing a farm's sustainability: Insights from resilience thinking. Int. J. Agric. Sustuain. 2010, 8, 186-198. [CrossRef]

12. Luers, A.L.; Lobell, D.B.; Sklar, L.C.; Addams, C.L.; Matson, P.A. A method for quantifying vulnerability, applied to the agricultural system of the Yaqui Valley, Mexico. Glob. Environ. Chang. 2003, 13, 255-267. [CrossRef]

13. Speranza, C.I. Buffer capacity: Capturing a dimension of resilience to climate change in African smallholder agriculture. Reg. Environ. Chang. 2013, 13, 521-535. [CrossRef]

14. Luers, A.L. The surface of vulnerability: An analytical framework for examining environmental change. Glob. Environ. Chang. 2005, 15, 214-223. [CrossRef]

15. Eakin, H.; Benessaiah, K.; Barrera, J.F.; Cruz-Bello, G.M.; Morales, H. Livelihoods and landscapes at the threshold of change: Disaster and resilience in a Chiapas coffee community. Reg. Environ. Chang. 2012, 12, 475-488. [CrossRef]

16. Tittonell, P. Livelihood strategies, resilience and transformability in African agroecosystems. Agric. Syst. 2014, 126, 3-14. [CrossRef]

17. Darnhofer, I.; Moller, H.; Fairweather, J. Farm Resilience for Sustainable Food Production: A Conceptual Framework; Working Paper; Lincoln University: Christchurch, New Zealand, 2008.

18. Scheffer, M.; Carpenter, S.; Foley, J.A.; Folke, C.; Walker, B. Catastrophic shifts in ecosystems. Nature 2001, 413, 591-596. [CrossRef] [PubMed]

19. Carpenter, S.; Walker, B.; Anderies, J.M.; Abel, N. From metaphor to measurement: Resilience of what to what? Ecosystems 2001, 4, 765-781. [CrossRef]

20. Beisner, B.E.; Haydon, D.T.; Cuddington, K. Alternative stable states in ecology. Front. Ecol. Environ. 2003, 1, 376-382. [CrossRef]

21. Suding, K.N.; Gross, K.L.; Houseman, G.R. Alternative states and positive feedbacks in restoration ecology. Trends Ecol. Evol. 2004, 19, 46-53. [CrossRef] [PubMed]

22. Folke, C.; Carpenter, S.; Walker, B.; Scheffer, M.; Elmqvist, T.; Gunderson, L.; Holling, C.S. Regime Shifts, Resilience, and Biodiversity in Ecosystem Management. Annu. Rev. Ecol. Evol. Syst. 2004, 35, 557-581. [CrossRef]

23. Scheffer, M.; Brock, W.; Westley, F. Socioeconomic mechanisms preventing optimum use of ecosystem services: An interdisciplinary theoretical analysis. Ecosystems 2000, 3, 451-471. [CrossRef]

24. Anderies, J.M.; Janssen, M.A.; Ostrom, E. A framework to analyze the robustness of social-ecological systems from an institutional perspective. Ecol. Soc. 2004, 9, 18. [CrossRef]

25. Shah, G.A.; Groot, J.C.J.; Shah, G.M.; Lantinga, E.A. Simulation of Long-Term Carbon and Nitrogen Dynamics in Grassland-Based Dairy Farming Systems to Evaluate Mitigation Strategies for Nutrient Losses. PLoS ONE 2013, 8, e67279. [CrossRef] [PubMed]

26. Groot, J.C.J.; Rossing, W.A.H.; Lantinga, E.A.; Van Keulen, H. Exploring the potential for improved internal nutrient cycling in dairy farming systems, using an eco-mathematical model. NJAS Wagening. J. Life Sci. 2003, 51, 165-194. [CrossRef]

27. Power, B.; Rodriguez, D.; DeVoil, P.; Harris, G.; Payero, J. A multi-field bio-economic model of irrigated grain-cotton farming systems. Field Crops Res. 2011, 124, 171-179. [CrossRef]

28. Janssen, S.; Van Ittersum, M.K. Assessing farm innovations and responses to policies: A review of bio-economic farm models. Agric. Syst. 2007, 94, 622-636. [CrossRef] 
29. Holling, C.S. Resilience of ecosystems; local surprise and global change. In Sustainable Development of the Biosphere; Clark, W.C., Munn, R.E., Eds.; Cambridge University Press: Cambridge, UK, 1986; pp. $292-317$.

30. Holling, C.S. Understanding the complexity of economic, ecological and social systems. Ecosystems 2001, 4, 390-405. [CrossRef]

31. Milestad, R.; Darnhofer, I. Building farm resilience: The prospects and challenges of organic farming. J. Sustain. Agric. 2003, 22, 81-97. [CrossRef]

32. Walker, B.; Gunderson, L.; Kinzig, A.; Folke, C.; Carpenter, S.; Schultz, L. A handful of heuristics and some propositions for understanding resilience in social-ecological systems. Ecol. Soc. 2006, 11, 13. [CrossRef]

33. Groot, J.C.J.; Rossing, W.A.H. Model-aided learning for adaptive management of natural resources: An evolutionary design perspective. Methods Ecol. Evol. 2011, 2, 643-650. [CrossRef]

34. Auger, A.; Bader, J.; Brockhoff, D.; Zitzler, E. Hypervolume-based multiobjective optimization: Theoretical foundations and practical implications. Theor. Comput. Sci. 2012, 425, 75-103. [CrossRef]

35. De Gobierno, S.H. Ayuntamiento Constitucional de Marcos Castellanos: Plan de Desarrollo Municipal. Available online: https://issuu.com/simarsureste/docs/plan_municipal_de_desarrollo_marcos (accessed on 14 November 2016).

36. Cortez-Arriola, J.; Groot, J.C.J.; Améndola Massiotti, R.D.; Scholberg, J.M.S.; Mariscal Aguayo, V.D.; Tittonell, P.; Rossing, W.A.H. Resource use efficiency and farm productivity gaps of smallholder dairy farming in North-west Michoacán, Mexico. Agric. Syst. 2014, 126, 15-24. [CrossRef]

37. Cortez-Arriola, J.; Rossing, W.A.H.; Améndola Massiotti, R.D.; Scholberg, J.M.S.; Groot, J.C.J.; Tittonell, P. Leverages for on-farm innovation from farm typologies? An illustration for family-based dairy farms in north-west Michoacán, Mexico. Agric. Syst. 2015, 135, 66-76. [CrossRef]

38. Cortez-Arriola, J.; Groot, J.C.J.; Rossing, W.A.H.; Scholberg, J.M.S.; Améndola Massiotti, R.D.; Tittonell, P. Alternative options for sustainable intensification of smallholder dairy farms in North-West Michoacán, Mexico. Agric. Syst. 2016, 144, 22-32. [CrossRef]

39. Groot, J.C.J.; Oomen, G.J.M.; Rossing, W.A.H. Multi-objective optimization and design of farming systems. Agric. Syst. 2012, 110, 63-77. [CrossRef]

40. Lizárraga, G.; Aguayo, A.; Garza, T.; Peñuñuri, F. Comparación de la producción de forraje de ballico italiano (Lolium multiflorum Lam) y cebada forrajera (Hordeum vulgare L.) solos y asociados. Técnica Pecuaria México 1980, 39, 17-24.

41. Abson, D.J.; Fraser, E.D.; Benton, T.G. Landscape diversity and the resilience of agricultural returns: A portfolio analysis of land-use patterns and economic returns from lowland agriculture. Agric. Food Secur. 2013. [CrossRef]

42. Brzezina, N.; Kopainsky, B.; Mathijs, E. Can Organic Farming Reduce Vulnerabilities and Enhance the Resilience of the European Food System? A Critical Assessment Using System Dynamics Structural Thinking Tools. Sustainability 2016, 8, 971. [CrossRef]

43. Xu, L.; Marinova, D.; Guo, X. Resilience thinking: A renewed system approach for sustainability science. Sustain. Sci. 2015, 10, 123-138. [CrossRef]

44. Schippers, P.; van der Heide, C.M.; Koelewijn, H.P.; Schouten, M.A.H.; Smulders, R.M.J.M.; Cobben, M.M.P.; Sterk, M.; Vos, C.C.; Verboom, J. Landscape diversity enhances the resilience of populations, ecosystems and local economy in rural areas. Landsc. Ecol. 2014, 30, 193-202. [CrossRef]

(C) 2016 by the authors; licensee MDPI, Basel, Switzerland. This article is an open access article distributed under the terms and conditions of the Creative Commons Attribution (CC-BY) license (http://creativecommons.org/licenses/by/4.0/). 